\title{
Interactions between Sympathomimetic Amines and Antidepressant Agents in Man
}

\author{
A. J. BOAKES, D. R. LAURENCE, P. C. TEOH, F. S. K. BARAR, L. T. BENEDIKTER, \\ B. N. C. PRICHARD
}

British Medical fournal, 1973, 1, 311-315

\section{Summary}

Intravenous infusions of phenylephrine, noradrenaline, adrenaline, and isoprenaline were given to healthy human volunteers after five to seven days on phenelzine, tranylcypromine, or imipramine, and cardiovascular responses were compared with those observed under control conditions. With monoamine oxidase inhibitors there was a 2-21 fold potentiation of the pressor effect of phenylephrine, but no clinically significant potentiation of cardiovascular effects of noradrenaline, adrenaline, or isoprenaline. With imipramine there was potentiation of the pressor effects of phenylephrine (2-3 fold), noradrenaline (4-8 fold), and adrenaline (2-4 fold); there were dysrhythmias during adrenaline infusions, but no noticeable or consistent changes in response to isoprenaline.

Noradrenaline and adrenaline in amounts contained in local anaesthetics used in dentistry are not likely to be significantly potentiated in otherwise healthy patients receiving monoamine oxidase inhibitors. Hazardous potentiation of their cardiovascular effects might occur in patients receiving tricyclic antidepressants.

Our observations do not indicate that the hazards associated with isoprenaline inhalation by bronchial

Clinical Pharmacology Section, Medical Unit, University College Hospital Medical School, London WC1E 6J]

A. J. BOAKES, M.sc., F.F.A. R.C.s., Wellcome Trust Research Fellow in Clinical Pharmacology (Present address: Departments of Pharmacology and Anaesthesia, Charing Cross Hospital, London W.6)

D. R. LAURENCE, M.D., F.R.C.P., Professor

P. C. TEOH, M.B., M.R.C.P., Smith and Nephew Fellow (Present address: Department of Medicine, University of Singapore, Malaysia)

F. S. K. BARAR, M.SC., M.D., Colombo Plan Scholar (Present address: Department of Pharmacology, S.N. Medical College, Jodhpur,
Rajasthan, India)

L. T. BENEDIKTER, M.D., Research Fellow (Present address: Department of Clinical Pharmacology, Karl Thomae Ltd., Biberach/Riss, W.

Germany)
B. N. C. PRICHARD, M.sc., M.R.C.P., Senior Lecturer

asthmatics would be increased by coincident therapy with a monoamine oxidase inhibitor or tricyclic antidepressant.

\section{Introduction}

Clinical practice is all too often punctuated by adverse reactions to drugs (Wade, 1970), and drug interactions form one example of these reactions (Herxheimer, 1967, 1969; Prescott, 1969). Laurence (1964) classified drug interactions as (1), predictable interactions that were predicted; (2), predictable interactions that were not predicted; and (3), unpredictable interactions.

Far too many adverse interactions have fallen into the second category-for example, the "cheese reactions" with monoamine oxidase inhibitors-and this category deserves special study, for an understanding of the errors of past practice should provide guidelines for future good practice.

The pressor hazards of indirectly acting sympathomimetic amines (Elis et al., 1967; Cuthbert et al., 1969) and of levodopa (Hunter et al., 1970) and dopamine (Horwitz et al., 1960) in patients on monoamine oxidase inhibitors have been well established. The "cheese reaction" has been attributed to the tyramine content of various foodstuffs, and this aspect of monoamine oxidase inhibitor interactions has been reviewed (Marley and Blackwell, 1970; Boakes, 1971).

In 1966 the then Committee on Safety of Drugs (now Medicines) sent a circular letter to all dental practitioners drawing their attention to possible hazards due to interaction between monoamine oxidase inhibitors and drugs used in dentistry. It was stated that the drugs to be used with caution include adrenaline and noradrenaline. Although there was some evidence of potentiation of the pressor effects of these catecholamines by monoamine oxidase inhibitors (Harrer et al., 1964; Fischbach et al., 1966), other workers found no evidence of potentiation either in animals (Rand and Trinker, 1968) or in man (Horwitz et al., 1960; Elis et al., 1967).

In view of the controversy which followed this warning based on conflicting evidence it was decided to perform interaction experiments in man with catecholamines and monoamine oxidase inhibitors, and, in addition, to observe the effects of a 
tricyclic antidepressant agent on the cardiovascular effects of catecholamines, for there was evidence that such an agent would potentiate the pressor effects of adrenaline and noradrenaline (Svedmyr, 1968).

\section{Method}

Four healthy male clinical pharmacologists (age range 30-48 years) gave their informed consent to act as volunteer subjects in the study, which was approved by the University College Hospital Medical School ethics committee.

The subjects received intravenous infusions of phenylephrine, noradrenaline, adrenaline, and isoprenaline under control conditions after the tricyclic agent imipramine $25 \mathrm{mg}$ three times a day for five days, after the hydrazine monoamine oxidase inhibitor phenelzine $15 \mathrm{mg}$ three times a day for seven days (two subjects), and after the non-hydrazine monoamine oxidase inhibitor tranylcypromine $10 \mathrm{mg}$ three times a day for seven days (two subjects).

Solutions were freshly prepared before infusion and contained ascorbic acid $1 \mathrm{mg} / \mathrm{ml}$ to limit oxidation of the amines. At each experiment the four sympathomimetic amines were infused in random order without the subject being aware of the order. The solutions were delivered from a Harvard infusion pump into the side arm of an intravenous cannula through which passed a continuous drip of $0.9 \%$ sodium chloride.

Before infusions started, each subject rested supine until blood pressure and heart rate had reached a steady state. Throughout the experiments the blood pressure was measured by means of the London School of Hygiene sphygmomanometer (Rose et al., 1964), which is designed to eliminate observer bias, and the rate and rhythm of the heart were continuously monitored by means of a Mingograph recorder.

Phenylephrine infusions were started at $50 \mu \mathrm{g} / \mathrm{min}$, and at five-minute intervals the rate of infusion was increased in logarithmic fashion to $100,200,400 \mu \mathrm{g} / \mathrm{min}$, etc. The purpose of the phenylephrine infusions in the subjects pretreated with phenelzine and tranylcypromine was to show that inhibition of amine oxidase had in fact occurred.

Noradrenaline infusions were started at $2 \mu \mathrm{g} / \mathrm{min}$, and at five-minute intervals the rate of infusions was increased in logarithmic fashion to $4,8,16 \mu \mathrm{g} / \mathrm{min}$, etc.

Adrenaline.-The technique used was as for noradrenaline.

Isoprenaline infusions were started at $1 \mu \mathrm{g} / \mathrm{min}$, and at fiveminute intervals the rate of infusion was increased in logarithmic fashion to $2,4 \mu \mathrm{g} / \mathrm{min}$, etc.

It was decided that infusions should be terminated when the systolic blood pressure exceeded $170 \mathrm{~mm} \mathrm{Hg}$ or when the heart rate increased by 40 beats/min or when the subject requested. It had previously been determined that during maximum effort of exercise the systolic blood pressure rose to levels greater than $170 \mathrm{~mm} \mathrm{Hg}$ without harm to the subjects. Occasion- ally, when resting heart rate was slow, the heart rate was allowed to increase by more than 40 beats/min if this caused no discomfort. After termination of an infusion the blood pressure and heart rate were allowed to return to preinfusion levels before starting the next infusion.

\section{Results}

The final (steady state) blood pressures and heart rates during infusions of each amine after the subjects had been pretreated with antidepressant were compared with the pressures and rates produced by equal concentrations of amines under control conditions. If an infusion was terminated before the end of a five-minute infusion period the pressure and rate at the time of termination were compared with those at an equivalent time in the control infusion. These results are summarized in the table. The significance of antidepressant-induced modifications of the response of blood pressure and heart rate to infusions of amines was determined by means of paired $t$ tests. The $\mathrm{P}$ values quoted are derived from two-tailed tests.

In the following account of results "pressor" effect refers to rise in systolic pressure, for in terms of clinical hazard it is this which is most relevant. The significance of changes in diastolic and mean blood pressure (diastolic plus one-third of the pulse pressure) is also shown in the table.

\section{MONOAMINE OXIDASE INHIBITORS}

For purposes of analysis the results of experiments in subjects pretreated with either phenelzine or tranylcypromine have been grouped together, for there were only two subjects on each. Significant potentiation of the pressor effect of phenylephrine occurred $(P<0.05)$, but there was no significant change in the blood pressure responses to noradrenaline, adrenaline, or isoprenaline. Isoprenaline-induced tachycardia was significantly antagonized $(P<0.02)$, but there were no changes in heart rate responses to the other amines.

Phenelzine $15 \mathrm{mg}$ three times a day for seven days was associated with no noticeable symptoms apart from lethargy in subject 2 . There were no significant changes in resting blood pressure or heart rate. The pressor effect of phenylephrine was potentiated two-fold, showing the inhibition of amine oxidase. The cardiovascular effects of noradrenaline and adrenaline were not significantly altered (see figs. 1 and 2 ). The blood pressure changes with isoprenaline were not significantly altered, but there was antagonism of isoprenaline-induced tachycardia.

Tranylcypromine $10 \mathrm{mg}$ three times a day for seven days was associated with lethargy, dry mouth, and constipation in both subjects taking it. Resting blood pressure and heart rate were not significantly changed. The pressor effect of phenylephrine

Summary of Results in the Cases under Study. Figures in Parentheses are Standard Errors

\begin{tabular}{|c|c|c|c|c|c|c|c|c|c|c|c|c|c|}
\hline & & \multicolumn{3}{|c|}{ Phenylephrine } & \multicolumn{3}{|c|}{ Noradrenaline } & \multicolumn{3}{|c|}{ Adrenaline } & \multicolumn{3}{|c|}{ Isoprenaline } \\
\hline & & Before & After & $\mathbf{P}$ & Before & After & $\mathbf{P}$ & Before & After & $\mathbf{P}$ & Before & After & $\mathbf{P}$ \\
\hline & Average dose: & \multicolumn{3}{|c|}{$200 \mu \mathrm{g} / \mathrm{min}$} & \multicolumn{3}{|c|}{$9 \mu \mathrm{g} / \mathrm{min}$} & \multicolumn{3}{|c|}{$18 \mu \mathrm{g} / \mathrm{min}$} & \multicolumn{3}{|c|}{$3 \mu \mathrm{g} / \mathrm{min}$} \\
\hline \multirow[t]{2}{*}{$\begin{array}{l}\text { 1) Imipramine } \\
25 \mathrm{mg} \text { t.d.s. } \\
\text { for five days } \\
(\mathrm{n}=4)\end{array}$} & $\left\{\begin{array}{c}\text { B.P.** } \\
\text { Systolic } \\
\text { Diastolic } \\
\text { Mean } \\
\text { Heart rate* }\end{array}\right.$ & $\begin{array}{r}143(9 \cdot 9) \\
89(1 \cdot 4) \\
107(4 \cdot 3) \\
45(3 \cdot 2) \\
\end{array}$ & $\begin{array}{r}173(0 \cdot 6) \\
108(4 \cdot 8) \\
130(3 \cdot 3) \\
50(4 \cdot 0)\end{array}$ & $\begin{array}{l}<0.05 \\
<0.05 \\
<0.02 \\
<0.01\end{array}$ & $\begin{array}{r}131(6 \cdot 4) \\
84(5 \cdot 6) \\
100(4 \cdot 4) \\
63(5 \cdot 2)\end{array}$ & $\begin{array}{r}174(1 \cdot 4) \\
99(1 \cdot 3) \\
124(0 \cdot 8) \\
53(2 \cdot 0)\end{array}$ & $\begin{array}{l}<0.05 \\
0.05 \\
<0.01 \\
\text { N.S. }\end{array}$ & $\begin{array}{c}123(10.2) \\
60(5.4) \\
81(6.9) \\
86(6.9)\end{array}$ & $\begin{array}{c}153(16 \cdot 1) \\
72(4 \cdot 4) \\
99(7 \cdot 8) \\
95(12 \cdot 2)\end{array}$ & $\begin{array}{l}<0.025 \\
<0.05 \\
<0.01 \\
\text { N.S. }\end{array}$ & $\begin{array}{r}109(8 \cdot 7) \\
49(5 \cdot 1) \\
69(6 \cdot 2) \\
121(5 \cdot 2) \\
\end{array}$ & $\begin{array}{r}104(7 \cdot 4) \\
50(3.7) \\
68(4 \cdot 7) \\
127(1 \cdot 9) \\
\end{array}$ & $\begin{array}{l}\text { N.S. } \\
\text { N.S. } \\
\text { N.S. } \\
\text { N.S. }\end{array}$ \\
\hline & Average dose: & \multicolumn{3}{|c|}{$225 \mu \mathrm{g} / \mathrm{min}$} & \multicolumn{3}{|c|}{$28 \mu \mathrm{g} / \mathrm{min}$} & \multicolumn{3}{|c|}{$28 \mu \mathrm{g} / \mathrm{min}$} & \multicolumn{3}{|c|}{$3.5 \mu \mathrm{g} / \mathrm{min}$} \\
\hline $\begin{array}{l}\text { 1) Monoamine } \\
\text { oxidase } \\
\text { inhibitor } \\
(n=4)\end{array}$ & $\left\{\begin{array}{l}\text { B.P.* } \\
\text { Systolic } \\
\text { Diastolic } \\
\text { Mean } \\
\text { Heart rate* }\end{array}\right.$ & $\begin{array}{l}138(8 \cdot 7) \\
88(2 \cdot 1) \\
104(4 \cdot 3) \\
44(3 \cdot 7)\end{array}$ & $\begin{array}{l}173(1 \cdot 8) \\
106(3 \cdot 6) \\
128(2 \cdot 9) \\
43(2 \cdot 7)\end{array}$ & $\begin{array}{l}<0.05 \\
<0.005 \\
<0.005 \\
\text { N.S. }\end{array}$ & $\begin{array}{r}167(4 \cdot 0) \\
104(4 \cdot 2) \\
125(4 \cdot 0) \\
54(2 \cdot 3)\end{array}$ & $\begin{array}{r}170(1 \cdot 1) \\
96(1 \cdot 7) \\
121(1 \cdot 3) \\
51(4 \cdot 3)\end{array}$ & $\begin{array}{l}\text { N.S. } \\
\text { N.S. } \\
\text { N.S. } \\
\text { N.S. }\end{array}$ & $\begin{array}{c}135(13 \cdot 2) \\
66(5 \cdot 2) \\
89(7 \cdot \cdot) \\
82(4 \cdot 8)\end{array}$ & \begin{tabular}{|c|}
$135(11.9)$ \\
$66(3.8)$ \\
$89(6.4)$ \\
$83(7.8)$
\end{tabular} & $\begin{array}{l}\text { N.S. } \\
\text { N.S. } \\
\text { N.S. } \\
\text { N.S. }\end{array}$ & $\begin{array}{r}110(9 \cdot 0) \\
48(4 \cdot 6) \\
68(5 \cdot 9) \\
127(1 \cdot 6)\end{array}$ & $\begin{array}{r}113(3.9) \\
50(3.9) \\
71(3.4) \\
109(4.5)\end{array}$ & $\begin{array}{l}\text { N.S. } \\
\text { N.S. } \\
\text { N.S. } \\
<0.02\end{array}$ \\
\hline
\end{tabular}

* The quoted levels of B.P. and heart rate are those produced by the maximum tolerated doses of sympathomimetic amines (see Method) after antidepressant compared with those levels produced by similar doses under control conditions.

†.S. = Not significant. 


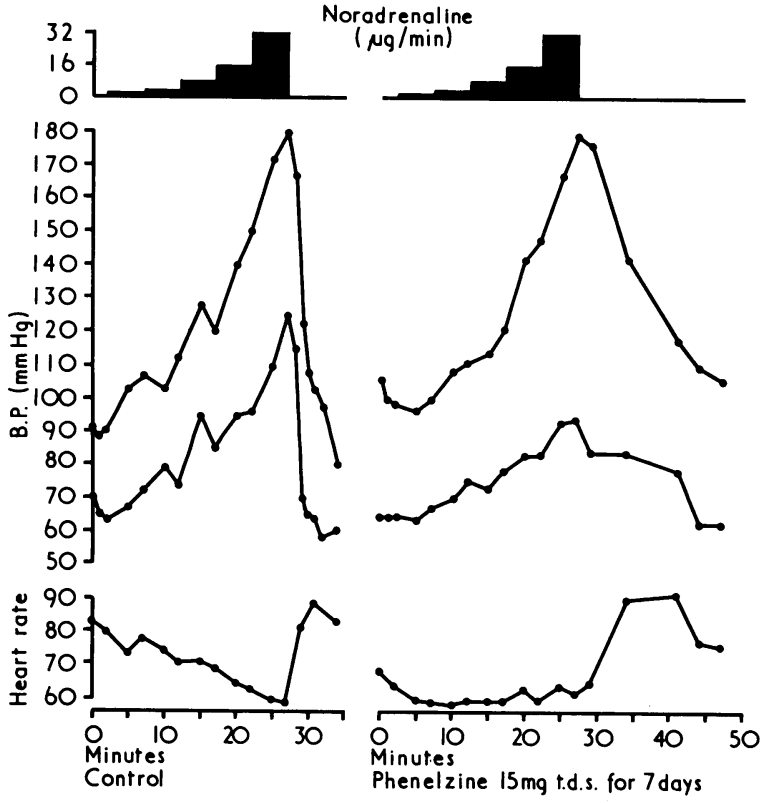

FIG. 1-Subject 1 , man, aged 48. Cardiovascular response to intravenous infusion of noradrenaline before and after phenelzine.

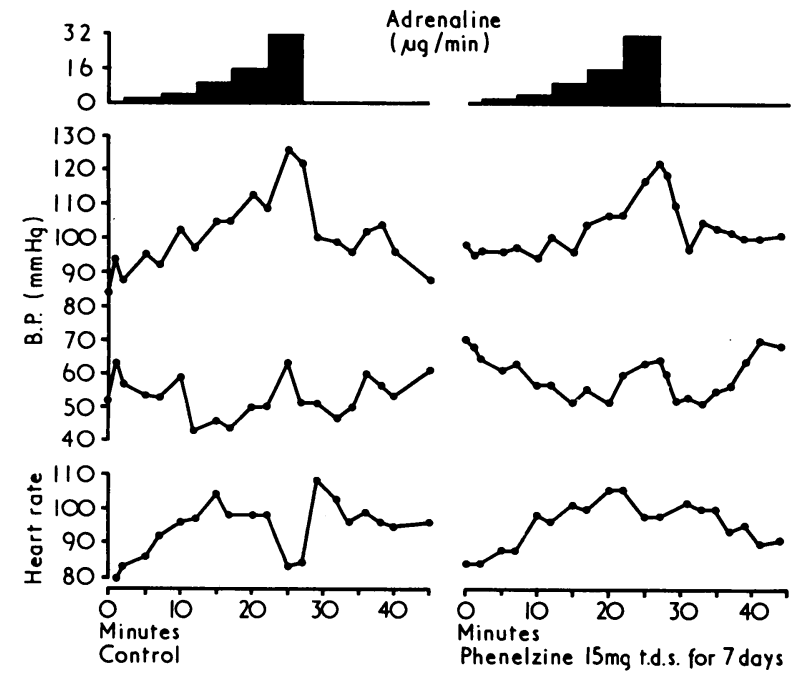

FIG. 2-Subject 2, man aged 30. Cardiovascular response to intravenous infusion of adrenaline before and after phenelzine.

was potentiated (up to $2 \frac{1}{2}$ times) showing the inhibition of amine oxidase (see fig. 3). In subject 3 there was a two-fold potentiation of pressor effect of the mid-range of concentrations of noradrenaline infused, but no potentiation of the lower or upper ranges. No potentiation of noradrenaline was observed at all in subject 4. There were no significant changes in response to adrenaline or isoprenaline infusions.

\section{IMIPRAMINE}

Imipramine $25 \mathrm{mg}$ three times a day for five days was associated with dry mouth, tachycardia, and an unpleasant feeling of "general uneasiness" in all subjects. There was an increase in both resting blood pressure $(P<0.05)$ and resting heart rate (not statistically significant).

There was a two-fold to three-fold potentiation of the pressor effect of phenylephrine $(P<0.05)$, a four-fold to eight-fold potentiation of noradrenaline $(P<0.005)$, and a two-fold to four-fold potentiation of adrenaline ( $P$ 0.025). There was a corresponding potentiation of bradycardia during the noradrenaline infusions, though this did not reach the level of significance. By contrast the bradycardia during phenylephrine infusions was less pronounced $(P<0.01)$ (fig. 4).

Some potentiation of adrenaline-induced tachycardia occurred in subject 2, but not in the other three subjects. However, striking changes in rhythm occurred-three subjects developed noticeable sinus arrhythmia, and the other subject (subject 1) developed numerous atrial ectopics, one ventricular ectopic, and periods of nodal rhythm.

Isoprenaline-induced tachycardia was modestly potentiated (nearly two-fold) in one subject (subject 4), but was unaltered in the other three.

There were no significant changes in the response of blood pressure to isoprenaline.

Infusions were associated with symptoms both under control conditions and after antidepressants. During phenylephrine infusions all subjects noticed piloerection on the scalp and at the


FIG. 3-Subject 3, man aged 32. Cardiovascular response to equipressor intravenous infusions of phenylephrine before and after tranylcypromine.



FIG. 4-Subject 2. Cardiovascular response to equipressor intravenous infusions of phenylphrine before and after imipramine. 
back of the neck, and were aware of the bradycardia. Noradrenaline produced "slow palpitations," and one subject consistently complained of a painful swelling in the throat which disappeared when the infusion was switched off without his knowledge. Adrenaline and isoprenaline, particularly the latter, produced "fast palpitations." Two subjects noticed "pressure on the chest" during infusions of high concentrations of adrenaline.

\section{Discussion}

"Many drugs used for the treatment of depression have disadvantages and dangers which seriously limit their usefulness" (British Medical fournal, 1971).

The pressor interaction between indirectly acting sympathomimetic amines and monoamine oxidase inhibitors has been well established. Orally administered tyramine is normally metabolized by amine oxidase in the gut wall and liver, so that very little gains access to the systemic circulation to exert a pressor effect. Pretreatment with monoamine oxidase inhibitor allows all or nearly all to enter the body and to exert a pressor action-hence the potentiated response. However, the mechanism of the potentiation of the pressor effect is not certain. Monoamine oxidase inhibitors raise monoamine levels in various tissues (Spector, 1963) and the potentiation of the pressor effect of indirectly acting sympathomimetic amines could be due to the release of greater amounts of noradrenaline from adrenergic nerve endings. This could happen whether or not the amines are substrates for amine oxidase. There are, however, objections to this mechanism, and Rand and Trinker (1968) suggested that monoamine oxidase inhibitors potentiate indirectly acting sympathomimetic amines purely by inhibiting their metabolism in the liver. Some amines-for example, amphetamine-are not substrates for amine oxidase, but it is known that monoamine oxidase inhibitors inhibit a wide range of enzymes. This might explain the potentiation of drugs such as pethidine (Clark and Thompson, 1972).

Adrenaline and noradrenaline are substrates for monoamine oxidase, but termination of their actions is mainly due to uptake into adrenergic neurons and metabolism by the enzyme catechol-o-methyl transferase (Axelrod, 1959). Thus, on theoretical grounds, monoamine oxidase inhibitors would not be expected to potentiate these catecholamines to a clinically important extent. Overall, no potentiation was observed in our experiments (see Results), confirming the findings of Elis et al. (1967) and Horwitz et al. (1960).

Cuthbert and Vere (1971) gave intravenous injections over 30 seconds of adrenaline and noradrenaline (up to an equivalent of $72 \mu \mathrm{g} / \mathrm{min}$ ) to subjects taking tranylcypromine and showed potentiation of pressor effect with noradrenaline and of tachycardia with adrenaline. This difference from our findings could well be related to the different doses used and the different technique of administration.

The clinical situation in which possible interaction is most likely is the use of local anaesthetics in dentistry. In spite of the differences between our results and those of Cuthbert and Vere, it is unlikely that patients on monoamine oxidase inhibitors are subject to clinically important extra risk from noradrenaline contained in local anaesthetic solutions. Nor are they subject to any extra risk from the myocardial reaction to adrenaline, provided they have healthy cardiovascular systems. The potentiation of adrenaline tachycardia observed by Cuthbert and Vere could subject the patient with ischaemic heart disease to extra risk (Occasional Notes, 1972*). There is evidence, however, that patients with ischaemic heart disease should not receive local anaesthetics containing adrenaline whether they

*These Occasional Notes were derived from the discussions of a working party appointed by the Adverse Reactions Subcommittee of the Committee on Safety of Medicines to review the safe use of vasoconstrictor-containing local anaesthetics in patients receiving antidepressant therapy. Drs. M. F. Cuthbert and D. W. Vere and two of us (A.J.B. and D.R.L.) were members of the working party. are taking monoamine oxidase inhibitors or not (Aellig et al. (1970).

Svedmyr (1968) found that the tricyclic antidepressant protriptyline potentiated the pressor action of noradrenaline about nine-fold and adrenaline about three-fold when these catacholamines were infused intravenously in man. Our experiments with imipramine (see figs. 5 and 6 ) showed a four-fold to eight-fold potentiation of noradrenaline and a two-fold potentiation of adrenaline. The mechanism is uncertain. Tricyclic agents inhibit the uptake of noradrenaline into adrenergic nerve endings (Iversen, 1967), and so there might be an increase in the local concentration of noradrenaline at receptor sites in tissues rich in adrenergic nerve endings. An increase in the sensitivity of adrenoceptors induced by imipramine and desipramine has been reported by Sigg et al. (1963a). Eble et al. (1971) thought that the contribution of either of these two mechanisms was small. Sigg et al. (1963b) and

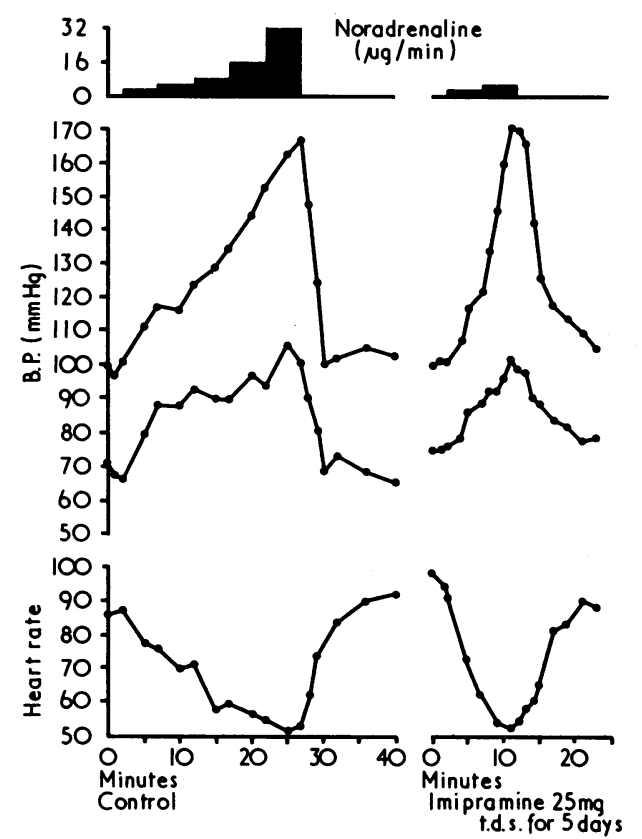

FIG. 5-Subject 2. Cardiovascular response to equipressor intravenous infusions of noradrenaline before and after imipramine.



FIG. 6-Subject 4, man aged 44. Cardiovascular response to intravenous infusion of adrenaline before and after imipramine. 
Eble (1964) have shown that imipramine blocks cardiovascular homoeostatic reflexes, but Boakes et al. (1973) have shown that potentiation of noradrenaline is not solely the result of block of vagal reflexes due to the atropine-like action of imipramine.

The wide range (four-fold to eight-fold) in potentiation of noradrenaline that we observed might have been due to different plasma levels of imipramine resulting from a fixed dose in subjects of different weight or from different rates of metabolism or from both. Alexanderson et al. (1969) showed that steadystate plasma levels of nortriptyline, given on a dose-per-body weight basis, vary greatly between subjects and that this is genetically determined, probably by rate of metabolism.

How hazardous is the administration of local anaesthetics containing noradrenaline to patients on tricyclics ? Boakes et al. (1972) reported a series of adverse reactions to local anaesthetics containing $1: 25,000$ noradrenaline $(40 \mu \mathrm{g} / \mathrm{ml})$. Of 15 patients, five certainly were and one "may have been" taking tricyclic agents. An episode of severe headache in a patient on protriptyline after $2 \%$ lignocaine with $1: 50,000$ noradrenaline $(20 \mu \mathrm{g} / \mathrm{ml})$ has been reported to a drug safety committee in another country (K. W. Lovel, personal communication, 1972). Goldman et al. (1970) showed that there was no potentiation of the pressor action of felypressin (phenylalanine-2-lysine-8-vasopressin) in dogs pretreated with desmethylimipramine. Although this observation has not yet been confirmed in man it seems that a local anaesthetic containing felypressin is safer than one containing noradrenaline in patients taking tricyclic agents.

Potentiation of the pressor action of adrenaline by imipramine is not pronounced (see fig. 6). Changes in blood pressure after local dental anaesthesia with $2 \%$ lignocaine and 1:80,000 adrenaline $(12.5 \mu \mathrm{g} / \mathrm{ml})$ are slight and potentiation by a tricyclic is not likely to be hazardous. However, adrenaline-induced heart rate and rhythm changes might be hazardously potentiated by a tricyclic. Imipramine produced no great changes in the heart rate response to adrenaline in the present subjects, though there was some potentiation of tachycardia in subject 2 . There were, however, changes in rhythm in all four subjects (see Results). Unexpected deaths have been reported in patients with heart disease who were taking amitriptyline (Coull et al., 1970) though not in those taking imipramine. A further study (Moir et al., 1972) has confirmed the amitriptyline findings and also revealed unexpected deaths in patients taking imipramine. A survey in the United States (Boston Collaborative Drug Surveillance Program, 1972) found that there was no association between tricyclic antidepressants and cardiotoxic effects, and that mortality in patients with pre-existing cardiovascular disease taking these drugs was similar to that in the control group. In view of the controversy it seems that felypressin is a safer vasoconstrictor than adrenaline in patients taking tricyclics.

Animal experiments have shown that pretreatment with a tricyclic agent reduces the pressor effects of indirectly acting amines (Costa et al., 1966; Bonaccorsi and Hrdina, 1967). Phenylephrine (both direct and indirect actions) was potentiated in our experiments (see fig. 4).

Both phenelzine and tranylcypromine antagonized isoprenaline-induced tachycardia (see Results). Imipramine produced a modest (nearly two-fold) potentiation of isoprenalineinduced tachycardia in one subject (subject 4), but no potentiation in any of the other three subjects. However, the resting heart rate was greater after imipramine and so the actual heart rates during isoprenaline infusions tended to be greater, by summation, than in the control situation, though the actual rises were similar. No abnormalities of rhythm were observed during isoprenaline infusions in any of the experiments. On this evidence it appears that coincident administration of a monoamine oxidase inhibitor or tricyclic would not increase the hazard of isoprenaline inhalation in bronchial asthmatics. More work would need to be done, however, before a definite assurance could be given.

We thank B. R. Graham for technical help.

Requests for reprints or copies of detailed tables of results for each subject should be sent to: Dr. A. J. Boakes, Clinical Pharmacology Section, Medical Unit, University College Hospital Medical School, University Street, London WC1E 6JJ.

\section{References}

Aellig, W. H., Laurence, D. R., O'Neil, R., and Verrill, P. J. (1970). British Fournal of Anaesthesia, 42, 174.

Alexanderson, B., Price-Evans, D. A., and Sjöqvist, F. (1969). British

Medical fournal, 4, 764.
Axelrod, J. (1959). Physiological Reviews, 39, 751.

Axelrod, J. (1959). Physiological Reviews, 39, 751.

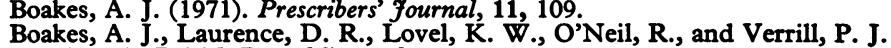
(1972). British Dental fournal, 133, 137.

Boakes, A. J., $\epsilon t$ al. (1973). To be published. onaccorsi, A., and Hrdina, P. (1967). Antidepressant Drugs, p. 149. Amsterdam, Excerpta Medica Foundation.

Boston Collaborative Drug Surveillance Program (1972). Lancet, 1, 529.

British Medical fournal, 1971, 1, 3.

Clark, B., and Thompson, J. W. (1972). British Fournal of Pharmacology, 44, 89.

Costa, B., Boullin, D. J., Hanimer, W., Vogel, W., and Brodie, B. B. (1966). Pharmacological Reviews, 18, 577.

Coull, D. C., Crooks, J., Dingwall-Fordyce, I., Scott, A. M., and Weir, R. D. (1970). Lancet, 2,590 .

Cuthbert, M. F., and Vere, D. W. (1971). British fournal of Pharmacology, 43, 472P.

Cuthbert, M. F., Greenberg, M. P., and Morley, S. W. (1969). British Medical fournal, 1,404 .

Eble, J. N. (1964). Fournal of Pharmacology and Experimental Therapeutics,

Eble, J. N., Gowdey, C. W., and Vane, J. R. (1971). Nature, 231, 181.

Elis, J., Laurence, D. R., Mattie, H., and Prichard, B. N. C. (1967). British Medical fournal, 2, 75

Fischbach, R., Harrer, G., and Harrer, H. (1966). Arzneimittel-Forschung, $16,263$.

Goldman, V., Àstrom, A., and Evers, H. (1970). Proceedings of the Third Asian and Australian Congress on Anaesthesiology, p. 517. Australia, Butterworths.

Harrer, G., Harrer, H., and Fischbach, R. (1964). Wiener Medizinische Wochenschrift, 114, 717.

Herxheimer, A. (1967). Drug and Therapeutics Bulletin, 5, 89.

Herxheimer, A. (1969). Prescribers' fournal, 9, 62.

Horwitz, D., Goldberg, L. T., and Sjoerdsma, A. (1960). Fournal of Laboratory and Clinical Medicine, 56, 747.

Hunter, K. R., Boakes, A. J., Laurence, D. R., and Sterne, G. M. (1970). British Medical Fournal, 3, 388.

Iversen, L. L. (1967). Uptake and Storage of Noradrenaline. London, Cambridge University Press.

Laurence, D. R. (1964). Proceedings of the European Society for the Study of Drug Toxicity, 4, p. 145. Amsterdam, Excerpta Medica.

Marley, E., and Blackwell, B. (1970). Advances in Pharmacology and Chemotherapy, 8, 185.

Moir, D. C., et al. (1972). Lancet, 2, 561.

Occasional Notes (1972). British Dental fournal, 132, 389.

Prescott, L. F. (1969). Lancet, 2, 1239

Rand, M. J., and Trinker, F. R. (1968). British fournal of Pharmacology and Chemotherapy, 33, 287.

Rose, G. A., Holland, W. W., and Crowley, E. A. (1964). Lancet, 1, 296.

Sigg, E. B., Soffer, L., and Gyermek, L. (1963a). fournal of Pharmacology and Experimental Therapeutics, 142, 13. Sigg, E. B., Osborne, M., and Korol, B. (1963b). Fournal of Pharmacology

Spector, S. (1963). Annals of the New York Academy of Sciences, 107, 856.

Svedmyr, N. (1968). Life Sciences, 7, 77.

Wade, O. L. (1970). Adverse Reactions to Drugs. London, Heinemann. 